\title{
XI1
}

\section{MORFOLOGIA URBANA: Um estudo para Poços de Caldas}

\section{URBAN MORPHOLOGY:A study for Poços de Caldas}

\author{
A. Luciana Valin Gonçalves Dias \\ Pontifícia Universidade Católica de Campinas, Brasil \\ lucianavgdias@hotmail.com
}

\begin{abstract}
RESUMO
O presente trabalho pretende abordar os aspectos da morfologia urbana tendo como estudo de caso a cidade de Poços de Caldas. Investigou-se a configuração dessa cidade, localizada no sul de Minas Gerais, e os diferentes processos de transformação que ocorreram no espaço urbano, desde a formação da cidade no século XVIII até a década de 1940. O trabalho utilizou como método inicial de investigação o entendimento sobre os estudos de morfologia urbana das escolas italiana, inglesa, francesa e portuguesa. A partir das cartografias levantadas para o recorte temporal escolhido, buscou-se analisar as modificações que ocorreram ao longo do tempo. A análise de Poços de Caldas demonstra uma hierarquia das transformações dos elementos na composição da paisagem urbana. Os estudos contribuíram para o entendimento do percurso histórico de Poços de Caldas como se fossem "lentes históricas", evidenciando as continuidades, as permanências e as transformações do espaço urbano.
\end{abstract}

Palavras-chave: morfologia urbana, cartografia histórica, Poços de Caldas.

Linha de Investigação: 1: Cidade e projeto

Tópico: Morfologia Urbana

\section{ABSTRACT}

The present work intends to approach the aspects of urban morphology using the city of Poços de Caldas as a case study. The configuration of this city located in the south of Minas Gerais, and the different transformation processes that took place in the urban space were investigated, from the formation of the city in the 18th century until the 1940s. The work used as an initial method of investigation the understanding on the studies of urban morphology in Italian, English, French and Portuguese schools. From the cartographies raised for the chosen time frame, we sought to analyze the changes that occurred over time. The analysis of Poços de Caldas demonstrates a hierarchy of the transformations of the elements in the composition of the urban landscape. The studies contributed to the understanding of the historical path of Poços de Caldas as if they were "historical lenses", showing the continuities, the permanences and the transformations of the urban space.

Keywords: urban morphology, historical cartography, Poços de Caldas.

Research line: City and project

Topic: Urban Morphology 


\section{XII

\section{Introdução}

O presente trabalho foi tema de uma dissertação de mestrado desenvolvida entre 2015 e 2016, tendo como estudo de caso Poços de Caldas (MG-Brasil), cidade que passou por muitas intervenções urbanísticas, provocando alterações na sua forma urbana ao longo do tempo. De acordo com a historiografia da região, as águas termais foram um instrumento civilizador desse território. A leitura e a interpretação dos aspectos físicos e formas da cidade, fundamentada nos aspectos históricos foi o método adotado na pesquisa, com o objetivo de compreender a configuração dessa estância balneária. O recorte temporal estudado percorre o período desde a formação do povoado dos "Campos das Caldas", no século XVIII, por volta de 1760, quando nasce um núcleo urbano a partir da cura pelas suas águas, até a década de 1940, quando em 30 de abril de 1946, o jogo foi proibido no Brasil, fato que alterou significativamente a vida econômica e social da localidade. O recorte espacial estabelecido abrange a área central da cidade de Poços de Caldas, tomando como ponto de partida o complexo hidrotermal do Parque José Afonso Junqueira: praças e jardins, o Palace Hotel, as Thermas Antônio Carlos, o Palace Cassino e algumas quadras do seu entorno.

A dissertação de mestrado foi dividida em três capítulos. O primeiro capítulo apresenta uma abordagem sobre os estudos de morfologia urbana existentes na Europa: na Itália, na França, na Inglaterra e em Portugal. O segundo capítulo apresenta uma revisão bibliográfica sobre a história da cidade de Poços de Caldas, estabelecendo uma periodização que buscou compreender a formação da paisagem urbana. $O$ terceiro capítulo apresenta uma leitura morfológica da cidade, a partir da aplicação de alguns conceitos e métodos. A partir da sobreposição da cartografia histórica e de plantas da cidade, foi possível compreender a gênese da paisagem citadina. Ainda foi abordado de que forma os estudos de morfologia urbana podem ser utilizados, e como os mesmos podem contribuir como ferramenta metodológica para o entendimento das cidades.

A pesquisa se estrutura a partir do levantamento da cartografia histórica e dos planos urbanísticos que foram desenvolvidos para a cidade de Poços de Caldas. As cartografias estudadas foram: o primeiro registro da localidade que é um documento datado de 1826, um levantamento de 1865, um plano urbanístico de 1872 , um trecho de uma planta de 1880, um plano de 1912, uma planta de 1927, uma planta da década de 1930 e um conjunto de plantas cadastrais de 1943, que foram elaboradas pelo Departamento Geográfico do Estado de Minas Gerais. A pesquisa teve como objetivo compreender a gênese e as transformções na forma urbana da cidade e contribuir como uma nova leitura e compreensão do espaço urbano de Poços de Caldas.

O estudo de morfologia urbana exige um domínio multidisciplinar: da formação da cidade, da sua história, da sua geografia, dos processos construtivos, dos aspectos sociais e econômicos, e principalmente de quem utiliza esses espaços. É necessário o cruzamento de diferentes leituras e informações para explicar a cidade. O estudo da morfologia pode ser considerado um valioso instrumento para refletir sobre a formação histórica da cidade e sobre os elementos que a compõem, contudo não se restringe apenas em explicá-la por meio da sua história, mas representa uma ferramenta para compreendê-la de fato.

Os métodos de análise da morfologia urbana defendem uma relação entre passado, presente e futuro, orientam a relação de partes consolidadas da cidade com novos projetos urbanos, orientam a relação do novo com o antigo, a memória e a identidade do local. É necessário entender todo o percurso histórico do lugar para se compreender o seu espaço, pois o estudo da cidade não se restringe apenas à forma, mas sim à sua complexidade, à sua alteração espaço-temporal e às relações inseparáveis entre a sociedade e o 


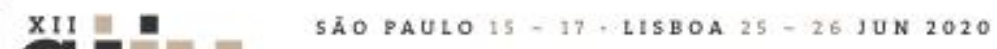

espaço construído. A forma não pode ser estudada isoladamente, ela se consolida a partir da interdisciplinaridade.

Além do caráter multidisciplinar, os métodos empregados nos estudos de morfologia urbana se estruturam a partir de instrumentos de análise diversos. O meio urbano pode ter diversas interpretações de acordo com os critérios a serem utilizados. Ao cruzarem-se os dados levantados pode-se explicar algo tão complexo quanto uma cidade. É uma divisão do meio urbano em partes, aos quais podemos classificar como "elementos morfológicos".

Segundo Lamas (2004):

Um estudo de morfologia urbana ocupa-se da divisão do meio urbano em partes (elementos morfológicos) e da articulação destes entre si e com o conjunto que definem - os lugares que constituem o espaço urbano. $O$ que remete de imediato para a necessidade de identificação e clarificação dos elementos morfológicos, quer em ordem à leitura ou análise do espaço, quer em ordem à sua concepção ou produção. (LAMAS, 2004: 38)

O estudo de morfologia urbana se divide em vários níveis, momentos e/ou recortes temporais de produção do espaço urbano. A cidade pode ser analisada em diversos aspectos para se estudar sua morfologia, tais como: o solo, os edifícios, o lote, o quarteirão, a quadra, as fachadas, os logradouros, as ruas, os traçados, os monumentos, as praças, a vegetação e o mobiliário urbano.

Para Lamas (2004), a concepção da forma urbana apóia-se em diferentes itens de compreensão, tais como as diferentes escalas: a da rua, a do bairro e a da cidade. A rua, podemos entender como a menor porção do espaço urbano, e a partir dela analisam-se diversos aspectos: fachadas, mobiliário urbano, pavimentos, cores, vegetação, calçamentos, monumentos isolados, etc. Quanto aos bairros, é a partir deles que se constrói a área urbana, são partes homogeneamente identificáveis. Já a cidade, é a verdadeira articulação entre todos os elementos urbanos, a ligação dos bairros, unindo todos os componentes das escalas inferiores (ruas e bairros).

\subsection{Poços de Caldas: um panorama da sua história}

A formação histórica de Poços de Caldas no recorte temporal dessa pesquisa, período compreendido entre 1760 e 1946, pode dividir-se em quatro fases significativas: a primeira fase, com a descoberta das águas sulfurosas e seus povoadores (1760 até aproximadamente 1800); a segunda fase com a fundação da cidade, aproximadamente entre 1800 e 1872; a terceira fase com a exploração das águas e o desenvolvimento da cidade por concessionários particulares, período entre 1872 e 1900; e a quarta fase do Estado no controle da estância hidromineral, período entre 1900 e 1946.

\subsubsection{Primeira fase (1760 até aproximadamente 1800)}

A região do "Campo das Caldas" foi desbravada, na segunda metade do século XVIII, por bandeirantes que penetraram o sul das Minas Gerais à procura de riquezas minerais. (ver figura 01) Como não eram comuns atividades agrícolas e pastoris em regiões mineradoras, a caça tinha grande importância para a subsistência 


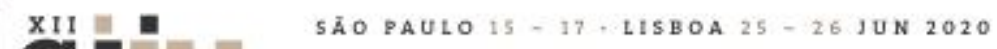

dos bandeirantes, até que seguindo as trilhas de animais silvestres chegaram à um vale cercado por montanhas e bosques, onde se descobriram cursos de águas borbulhantes. (SALLES, 1993: 3-4)

E a lenda do vale milagroso correu célere... Entre ipês floridos e aprumados pinheiros, no fundo da perambeira, à margem de pedregoso ribeirão havia uma água que nascia quente, que endireitava estropiados, limpava os tinhosos, fechava chagas e curava mazelas; e dava saúde; e dando saúde, dava direito de viver, de lutar, de ser feliz. Era só mergulhar o corpo nos poços nevoentos e cálidos, para sentir a água untosa, balsâmica, milagrosa... (MOURÃ̃O, 1998: 5)

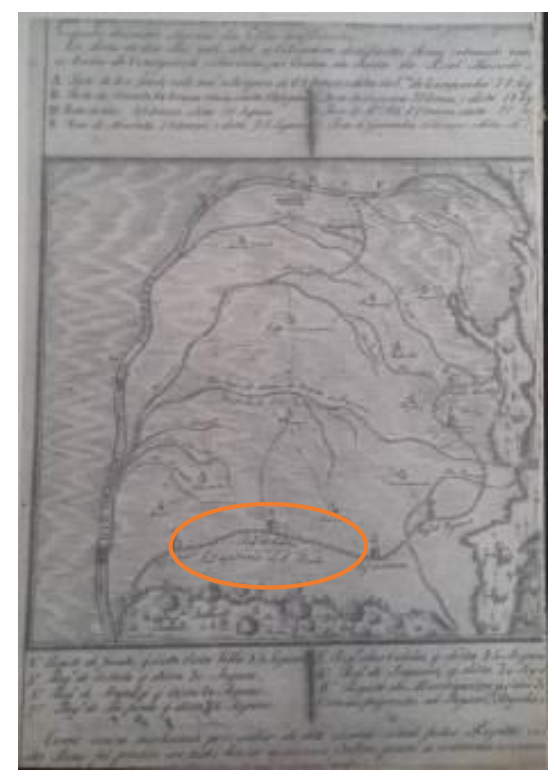

Fig. 01 Este mapa faz parte da Carta do Termo da Vila de Campanha da Princesa, de 29 de janeiro de 1802 . O destaque é para o Registro das Caldas, no limite entre as Capitanias de Minas e São Paulo. Fonte: (OTTONI, 1960: Estampa 10)

Poços de Caldas remonta sua concepção muito diferente do que era habitual no período colonial no Brasil, onde a formação das vilas estava vinculada à construção da Capela, do estabelecimento do Pelourinho, da demarcação do rossio, da consolidação das Casas de Câmara e Cadeia. O povoado do "Campo das Caldas" tem na sua origem uma particularidade em relação à maioria das cidades brasileiras, visto que seu desenvolvimento se deu pela descoberta das águas sulfurosas que proporcionavam a cura de doenças a partir dos banhos termais. A formação dos povoados e freguesias se deu ao longo das rotas de abastecimento. No caso de Poços de Caldas, as águas sempre estiveram ligadas ao seu processo civilizador. No entorno das nascentes termais deu-se a origem do povoado que passou a se chamar Nossa Senhora da Saúde das Águas de Caldas.

Esta era uma região de difícil acesso e de grande disputa pelos governos das capitanias de São Paulo e de Minas Gerais. A Comarca do Rio das Mortes foi uma das três primeiras existentes na Capitania das Minas Gerais, sendo instituída em 1714, tendo como sede a Vila de São João Del Rei e se subdividiu em 08 Têrmos: São João Del Rei, Jacuí, Baependi, Campanha da Princesa, Barbacena, Queluz, São José e Tamanduá. (OTTONI, 1960:74) Campanha da Princesa foi a Vila mais antiga do sul de Minas Gerais, constituída em 1798 e a região que viria a ser a cidade de Poços de Caldas fazia parte de seu termo. 


\section{XI1}

\subsubsection{Segunda fase (1800 até 1872$)$}

A palavra "Caldas" deriva do latim "Calidus", que significa quente (feminino / Cálida), que é usada na língua portuguesa para designar todas as águas minerais de temperatura elevada. (MEGALE, 2002: 12)

O Major Joaquim Bernardes da Costa Junqueira, nasceu em 1792, em Baependi, Minas Gerais. Seu pai dirigiu-se à região dos Poços entre 1812 e 1815 para se beneficiar das águas termais. Seduzido pelas pastagens naturais, junto com seus filhos: Joaquim Bernardes Junqueira e José Bernardes da Costa requereram sesmarias na "Paragem do Ribeirão Pinhal", da Freguesia de "Nossa Senhora do Patrocínio do Rio Verde das Caldas", Têrmo da Vila da Campanha da Princesa da Comarca do Rio das Mortes. Foram concedidas ao Major Joaquim Bernardes, terras devolutas no Ribeirão de Curitiba. Em 1818, esteve no povoado tratando de sua saúde, o Governador de Minas Gerais, Dom Manoel Francisco de Portugal e Castro, tornando-a muito conhecida. Os campos do planalto eram excelentes pastagens naturais e possuíam águas que "curavam". Os poços sulfurosos começaram a atrair pessoas de várias partes do Brasil, que vinham à procura de cura para suas doenças.

Ainda em 1819, foram atendidos os primeiros pedidos de sesmaria encaminhados ao governo mineiro desde que a região das Caldas se incorporara definitivamente a Minas Gerais. Assim, em 1826, cumpriu-se uma ordem do Governo para que o Juiz de Fora da Vila de Campanha da Princesa, Presidente Dr. Agostinho de Souza Loureiro, fosse para o "Campo das Caldas", hoje a cidade de Poços de Caldas, com a finalidade de fazer uma inspeção no local e tomar as devidas providências, onde procedeu, em 1826, o primeiro registro gráfico sobre as nascentes das águas termais e o que existia naquele povoado. O "Campo das Caldas" já era uma pequena povoação, cogitando-se abertura de ruas, construção de um hospital, um cemitério já existente, abriram-se poços e identificaram-se as nascentes como se pode observar a seguir no mapa levantado (ver figura 02). Os banhos eram feitos em tinas e em tanques abertos ao lado das fontes cercadas por esteiras de vedação, eram muito precários, mas mesmo assim iam sendo disseminados na região pelos seus benefícios. (OTTONI, 1960: 94)

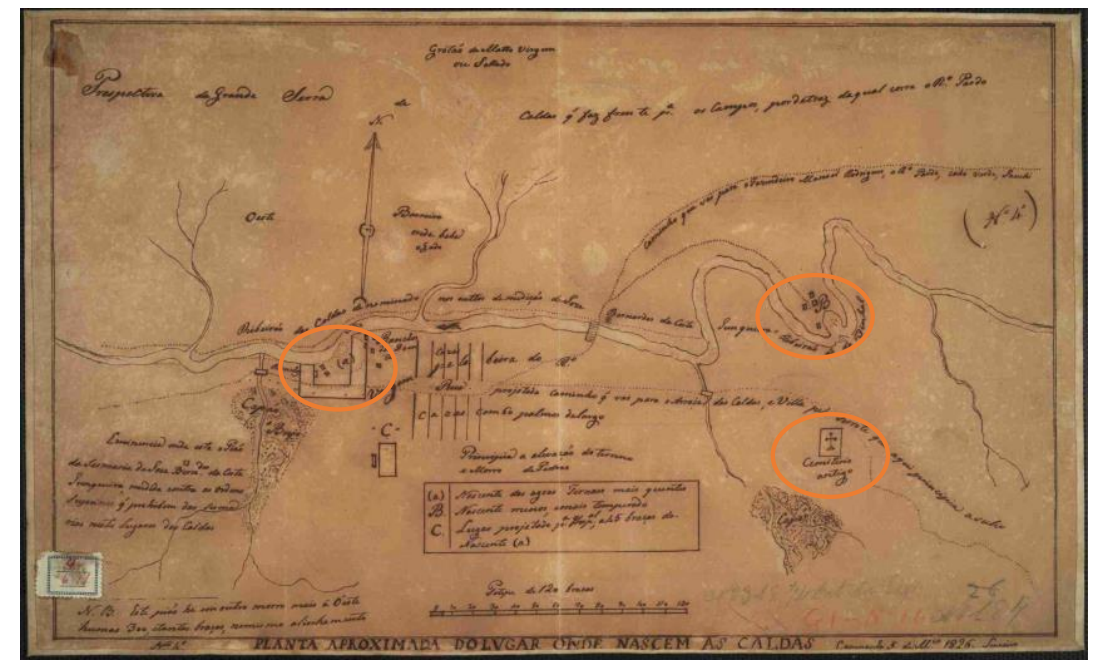

Fig. 02 Primeiro registro da povoação em 1826. Assinalados vêem-se as duas nascentes e o resgitro do cemitério antigo. Fonte: (LOUREIRO, 1826) 


\section{XII}

Em 1865, o Governo de Ouro Preto mandou ao "Campo das Caldas" o Engenheiro Dr. Martiniano da Fonseca dos Reis Brandão, para fazer uma planta do povoado (ver figura 03), orçar obras e proceder à desapropriação de terras que já pertenciam a um dono, o sesmeiro Joaquim Bernardes da Costa Junqueira e seus herdeiros. Segundo Ottoni (1960), em 30 de abril de 1865 foi assinado o Termo de doação de 26,5 alqueires à Província de Minas Gerais, obtidos pelo Engenheiro Martiniano da Fonseca dos Reis Brandão. Assim, foi desenvolvido um mapa em 1865 por esse engenheiro Brandão, que demonstrava que era uma região alagadiça, toda sulcada por córregos e ribeirões, indicavam os caminhos por onde os tropeiros passavam pela região e não havia indícios de nenhuma construção. A partir de 1865, a Província de Minas destacou muitos engenheiros para projetarem, orçarem e executarem melhoramentos no povoado.

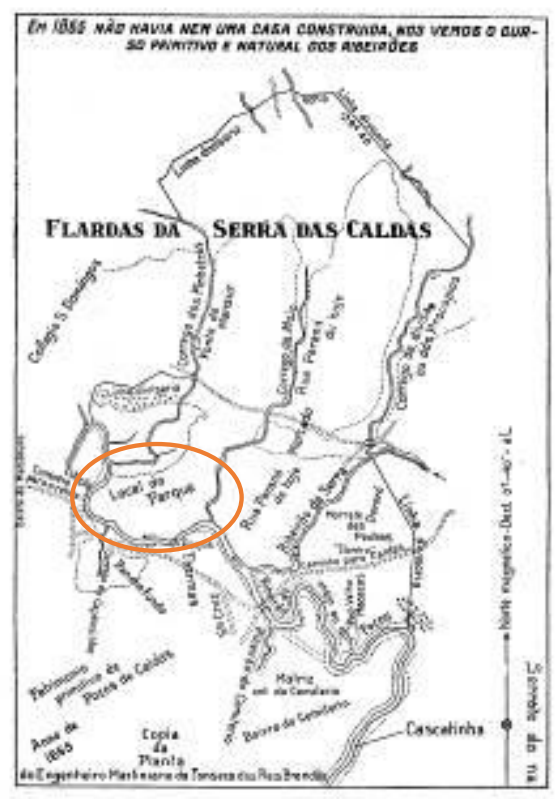

Fig. 03 Cópia da Planta do Engenheiro Martiniano da Fonseca dos Reis Brandão, em 1865. Assinalado vemos o local do atual Parque José Afonso Junqueira. (Fonte: MEGALE, 2002: 24)

No fim de 1872, o Presidente da Província Dr. Joaquim Floriano de Godoy desapropriou mais áreas, mandou iniciar a construção de balneários o que promoveu um desenvolvimento na cidade. Foram enviadas também ao Dr. Floriano Godoy, as análises das águas minerais e termais, e assim se compunham novas visões de uma estância moderna, que se consolidava com caráter de cura e lazer que se via nascer na Mantiqueira desde que se começou a difundir os relatos de curas milagrosas. Assim inicia-se a fundação de uma nova estância balneária no Brasil.

O Presidente da Província, Dr. Joaquim Floriano de Godoy, submeteu diligências para a fundação do povoado. Juntamente com um ofício, foi encaminhado à ele o projeto de implantação do povoado, cujos alinhamentos seriam norte-sul, leste-oeste. Entretanto ao fazer a locação, o Engenheiro Soares do Couto inclinou $21^{\circ} \mathrm{NE}$. Tinham instruções para demarcar terrenos, firmar limites, levantar a planta da futura povoação e planejar um estabelecimento provisório com condições higiênicas até ser construído um balneário definitivo (OTTONI, 1960: 109). Assim, em 1872, surge o primeiro plano de ordenamento proposto 


\section{XI1}

para o povoado e os princípios urbanísticos do final do século XIX são aplicados na localidade. (ver figura 04) O povoado foi se desenvolvendo e por volta de 1874, iniciaram-se estudos técnicos, delimitação de caminhos e estudos dos traçados iniciais para a construção do Ramal da Mogyana que viria se estabelecer na região, proveniente do percurso que partia de Campinas, no interior de São Paulo.
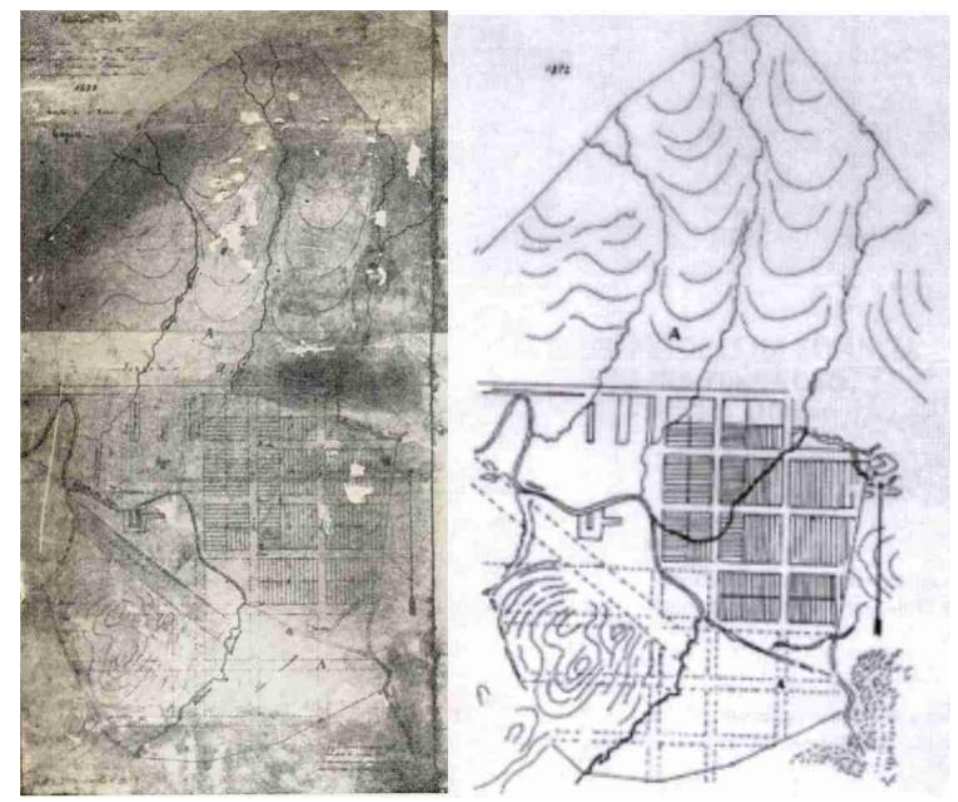

Fig. 04 À esquerda, mapa elaborado em 1872 para a estruturação do povoado. Fonte: (OTTONI, 1960: Estampa 15) e à direita: Redesenho do Mapa de 1872. Fonte: (MOURÃO, 1998: 18-19)

\subsubsection{Terceira fase (1872 até 1900)}

Poços de Caldas obteve sucesso no seu desenvolvimento, graças ao empenho de um conhecido "quarteto construtor". O "Quarteto construtor" foi uma expressão utilizada por Benedictus Mário Mourão (1998) e era composto pelas seguintes figuras: o fazendeiro Agostinho Junqueira, jovem filho do sesmeiro que doou as terras para a formação do povoado; o Dr. Pedro Sanches, médico e idealista que ajudou a tornar o povoado conhecido pelos tratamentos termais e os benefícios das suas águas; João Batista Pansini, jovem e habilidoso construtor italiano e Antônio Teixeira Diniz, um potencial empreendedor.

A estância passou por várias administrações, associações e concessionários que tentavam melhorar as condições da cidade e desenvolvê-la, porém sem muito sucesso. Foram muitas as associações que tentaram implantar projetos e obras na Freguesia. As Caldas foram subordinadas à diversas vilas entre elas: Jundiaí, Mojimirim e Campanha da Princesa. Até que a Freguesia foi elevada à categoria de cidade após a Proclamação da República, em 19 de maio de 1890 passando a se chamar: Poços de Caldas, nomeando um Conselho de Intendência Municipal, tornando-se um município autonômo.

No início do século XX, Poços de Caldas tinha como principais fontes de recursos o uso das águas medicinais, a pecuária e as lavouras de café. Em 22 de outubro de 1886, foi inaugurado oficialmente o Ramal de Caldas da Estrada de Ferro Mogyana para facilitar o transporte e proporcionar conforto às pessoas que 


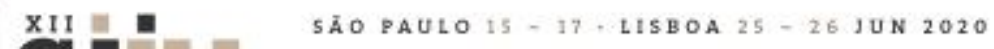

vinham usufruir dos tratamentos termais. A inauguração oficial contou com a presença do Imperador D. Pedro II e grande comitiva do Governo Imperial.

A estrada de ferro foi sem dúvida a mola da evolução econômica e social da jovem estância hidromineral. Transportava os produtos da terra e trazia as mais recentes conquistas culturais, artísticas e técnicas da Corte Imperial. Vários fazendeiros paulistas frequentavam os banhos termo sulfurosos e muitos deles construíram belas residências, que ainda hoje causam admiração aos visitantes da cidade. (MEGALE, 2002: 30)

A partir da chegada da ferrovia, a Vila passou a se desenvolver ainda mais, os "saberes" iam chegando à estância com maior facilidade e rapidez. Foi um período onde palacetes, chalés e casarões imponentes começaram a ser construídos. No final do século XIX, a cidade já vivia da grande circulação de pessoas que vinham se curar de moléstias diversas em suas águas termais. Era uma cidade voltada para a cura e o lazer. Poços de Caldas atraiu muitos paulistas que investiram na cidade. Fazendeiros de café e capitalistas de São Paulo construíram numerosas mansões na estância com influências européias e ecléticas, com novas soluções arquitetônicas. A vinda de arquitetos, engenheiros e construtores estrangeiros modificou as técnicas construtivas que eram utilizadas até aquele momento. Muitas casas e palacetes foram construídos aos moldes europeus mais requintados.

\subsubsection{Quarta fase (1900 até 1946)}

Em 04 de janeiro de 1905, foi criada a Prefeitura, pelo Presidente de Minas Gerais por meio de decreto, onde a administração seria exercida por um Conselho Deliberativo e um Prefeito nomeado pelo Governo do Estado. Em 1906, assinou-se um contrato que formou a Companhia Termal de Poços de Caldas. (MEGALE, 2002: 33)

No contrato com a Companhia Thermal de Poços de Caldas previa-se muitas melhorias para a localidade, tais como: abastecimento de águas em toda a zona urbana, rede de esgotos, retificação e canalização dos ribeirões, macadamização das ruas, ajardinamentos, construção de um grande hotel com todas as condições de conforto e higiene com estabelecimento balneário, um teatro, um cassino, um parque e arborização da grande avenida em direção à estação da Mogyana.

O período da administração entre dezembro de 1909 a outubro de 1918, foi muito promissor. Transformou a pequena Vila em uma Estância Hidromineral. Contratou o arquiteto José João Piffer e o irmão engenheiro Otto Piffer para realizar importantes projetos na cidade, entre eles: o edifício da Prefeitura, construção do Grande Hotel, do Cassino, do Teatro Polytheama e remodelou o antigo Mercado. A primeira grande obra realizada por Piffer foi a construção da Igreja Matriz de Nossa Senhora da Saúde em 1910. Embelezou a Vila com a arborização no traçado das suas avenidas, construíram várias pontes entre elas a da Praça Columbia, macadamizou as ruas da cidade propondo alteração dos nomes das mesmas, homenageando os Estados Brasileiros. (MEGALE, 2002: 59)

A estância não parava de prosperar e, assim, na década de 1920, o Estado decidiu investir efetivamente na estância e nesse grande projeto foi proposto construir o novo Complexo do Parque José Afonso Junqueira que contemplava um grande hotel de luxo, um cassino e um novo edifício destinado às termas. Estas novas construções envolviam grandes nomes na época da engenharia, arquitetura e paisagismo. Os três edifícios 
projetados pelo arquiteto Eduardo Vasconcelos Pederneiras foram implantados em meio aos jardins elaborados por Reynaldo Dieberger, e para os projetos de saneamento e abastecimento de água da cidade, o renomado engenheiro sanitarista Saturnino de Brito foi o escolhido. $O$ traçado da cidade de Poços de Caldas foi definido por vias construídas ao longo do curso de seus ribeirões, como eixos estruturadores do tecido urbano, e a partir das mesmas desenvolveu-se o traçado de outras ruas e bairros, característicos da sua paisagem. Os tratamentos com as terapias termais iniciaram um processo de melhoramentos no espaço físico da cidade balneária, uma vez que além dos tratamentos, o divertimento e o lazer também faziam parte da cura. A beleza e o luxo da cidade atraíam cada vez maior número de pessoas em busca de cura, mas também veranistas. A necessidade de espaços com mais qualidade, arborizados e sãos ia transformando a paisagem de Poços de Caldas. Instalava-se uma nova maneira de urbanizar a estação hidromineral. $O$ espaço dos tratamentos termais não era apenas local de sanar doenças, mas inseria novas práticas sociais e culturais. Era uma localidade aprazível com hotéis, passeios, bailes, cassino, apresentações e shows de renomados artistas brasileiros da época.

A Descoberta da penicilina como antibiótico (1940) e a proibição dos jogos de azar no Brasil no Governo de Eurico Gaspar Dutra (1946), foram dois importantes acontecimentos que afetaram a fonte de recursos econômicos da estância, contribuindo para um período de decadência em Poços de Caldas. Não só o turismo tinha se desenvolvido neste período histórico, mas todos os setores da vida pública. (MEGALE, 2002: 37)

Houve uma grande necessidade de se encontrarem novas alternativas para movimentar a cidade. Optou-se, então, pelo desenvolvimento da extração de riquezas minerais no Planalto de Poços de Caldas. A exploração de minérios, entre eles: o zircônio, o manganês, o urânio e principalmente a bauxita se tornaram grande fonte de renda para o Município.

\subsection{Os métodos da morfologia urbana aplicados ao estudo de caso}

A formação histórica de Poços de Caldas foi dividida em quatro fases significativas, cada uma delas imprime suas marcas na paisagem urbana e corresponde à produção de registros cartográficos e de planos que demonstram as estratégias de ocupação do território e de desenvolvimento da cidade. Essas fases podem ser entendidas como quatro "Períodos Morfológicos" e seus principais registros permitem compreender a sobreposição das intervenções no espaço. A análise foi construída mediante três procedimentos. A seguir, será demonstrado a aplicação de cada procedimento que estrutura a análise da forma urbana no periodo estudado.

\subsubsection{Procedimento 01}

No primeiro procedimento utilizando-se como base a planta cadastral de Poços de Caldas de 1943 (ver figura 05), foi feita a sobreposição da imagem das cartografias antigas para fazer uma comparação com os dados históricos relevantes. Foram redesenhadas essas plantas cadastrais para serem sobrepostas e "lidas" ao serem confrontadas. Os estudos do tecido urbano estabelecem ligações entre os elementos: ruas, parcelas e edificações. Ao serem analisados os grandes traçados viários revelam estruturas monumentais e as ligações com os espaços livres, os monumentos e os edifícios públicos. Um monumento ou edifício público pode ser 


\section{XII}

Seminário Internacional de

Seminario Internacional de Investigaçà em Urbanismo Investigacion en Urbanismo

um gerador de traçados. A permanência de um determinado tipo de parcelamento também pode contribuir para a conservação de bairros e espaços construídos.

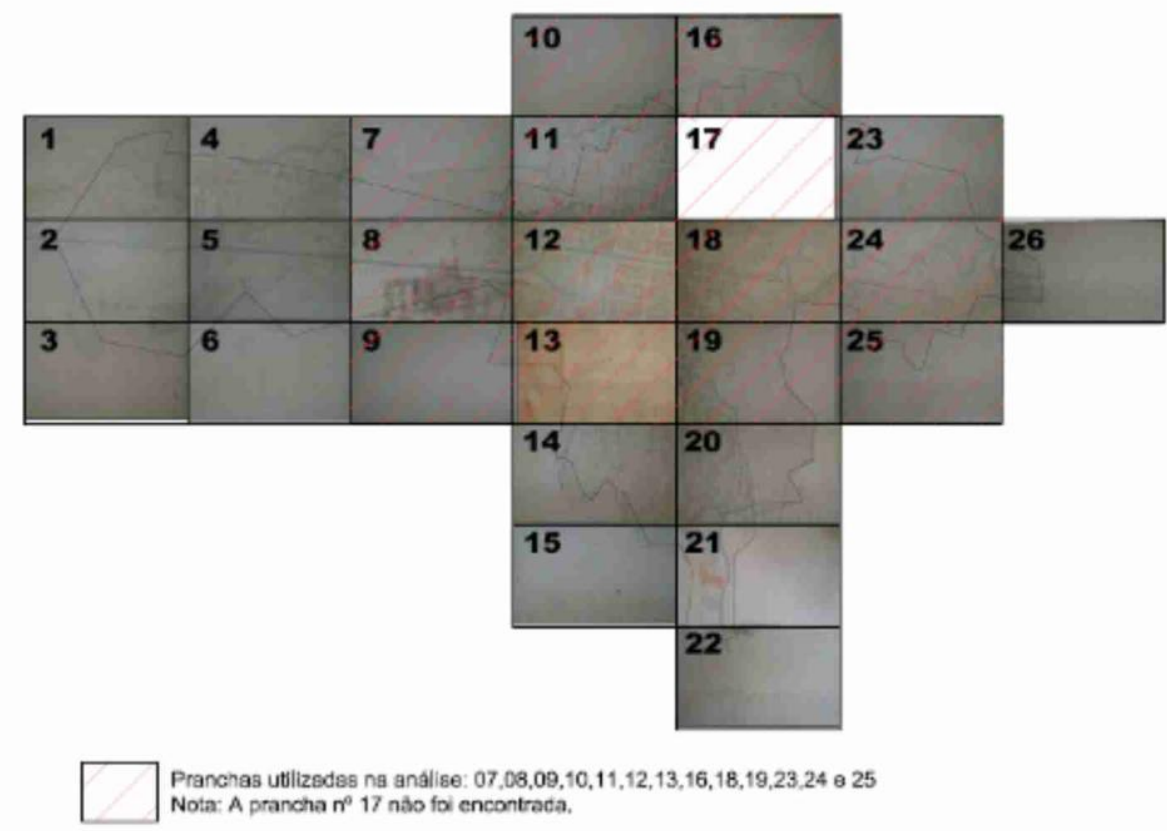

Fig. 05 Levantamento Cadastral de Poços de Caldas em 1943 - articulação de 26 pranchas. Fonte: Prefeitura Municipal de Poços de Caldas - Secretaria de Planejamento de Poços de Caldas. 


\section{XII}

Seminário Internacional de

Seminario Internacional de Investigaçào em Urbanismo

\section{П- !-}

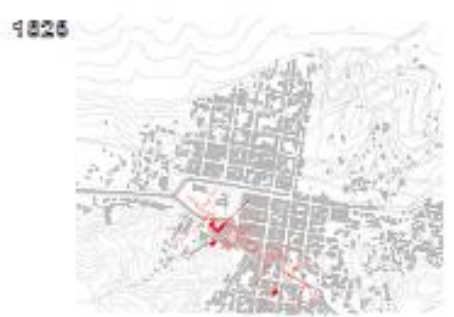

1838

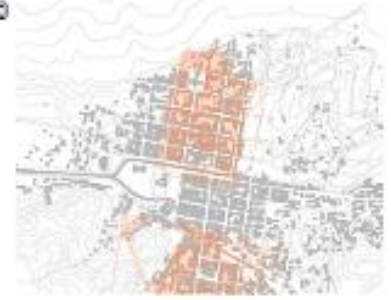

4853

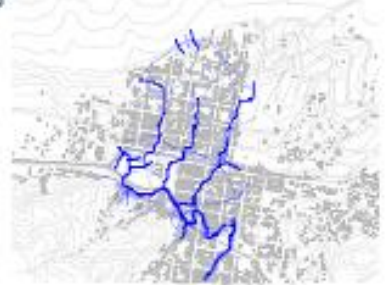

1927

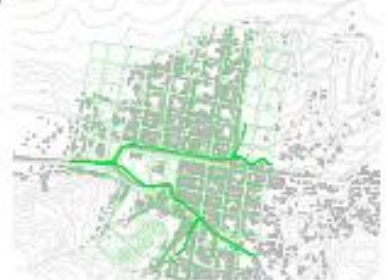

9872

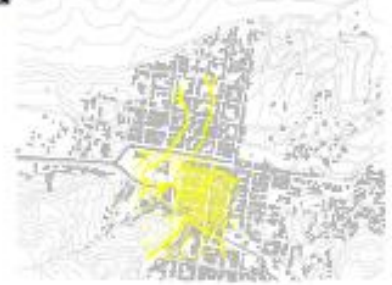

\$ุด

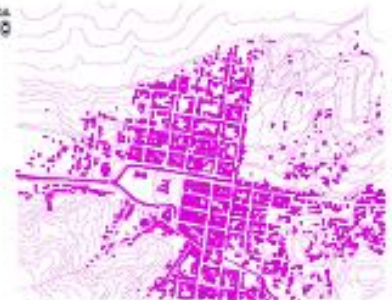

Fig. 06 Conjunto de sobreposições de mapas para entender o desenvolvimento da cidade, usando a base cartográfica de 1930, sobre as cartografias históricas de: 1826, 1865, 1872, 1880 e 1927. (DIAS, 2016: 3.17)

A seguir em destaque, ampliou-se a "lente" de 1865 para melhor compreensão da metodologia aplicada. A base cartográfica da década de 1930 em sobreposição à cartografia de 1865. (ver figura 07) Ao fazer-se essa sobreposição, fica evidente como a implantação da cidade com a presença de um traçado regular, com ruas largas, quadras definidas e lotes demarcados se impõe sobre o percurso dos recursos hídricos existentes no território.

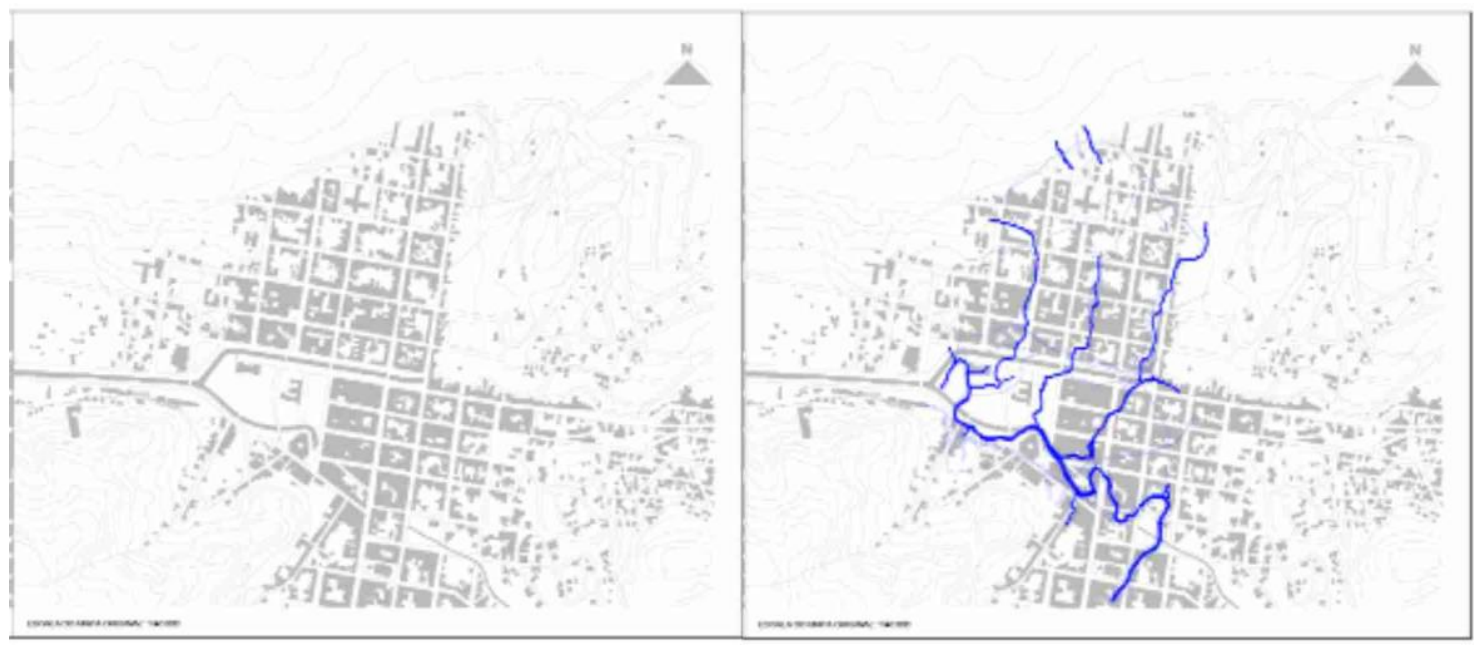

Fig. 07: Metodologia aplicada de sobreposição de cartografias. Em cinza a base de 1930 e em azul o redesenho da cartografia de 1865. Fonte: (DIAS, 2016) 


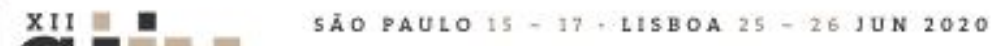

\subsubsection{Procedimento 03}

No terceiro procedimento, foi utilizada a base cartográfica de 1943, e elaborou-se uma análise mais detalhada de algumas quadras (recorte com quatro quarteirões) no entorno da Praça Pedro Sanches, analisando os tipos morfológicos existentes com as bases conceituais de Philippe Panerai: quadras, ruas e lotes deste tecido urbano. Elaborou-se ainda estudos tridimensionais volumétricos para reconstruir a configuração urbana deste tecido. O termo "tecido urbano" remete a diversos significados, entre eles aos produtos têxteis; aos tecidos vegetais e ósseos; e à estruturação de um conjunto, arcabouço ou preenchimento. Quando aplicado à cidade, enuncia a continuidade, renovação, permanências e variações. (PANERAI, 2014: 77)

Segundo Panerai, a respeito do tecido urbano:

Ele explica a constituição das cidades antigas e responde às questões levantadas pelo estudo das urbanizações recentes. Ele pressupõe uma atenção tanto ao banal quanto ao excepcional, tanto às ruas comuns e às edificações corriqueiras quanto às regulamentações e aos monumentos. [...] O tecido urbano é constituído pela superposição ou imbricação de três conjuntos: a rede de vias, os parcelamentos fundiários e as edificações. (PANERAI, 2014: 77-78)

Os estudos do tecido urbano estabelecem ligações entre os elementos: ruas, parcelas e edificações. Ao serem analisados os grandes traçados viários revelam estruturas monumentais e as ligações com os espaços e edifícios públicos. Um monumento ou edifício público pode ser um gerador de traçados. A permanência de um determinado tipo de parcelamento também pode contribuir para a conservação de bairros e espaços construídos.

Segundo Panerai (2014),

A observação de plantas cadastrais representadas de modo que ressalte mais os limites das propriedades do que a implantação dos edifícios fornece indicações que, confrontadas com a análise in situ, garantem um bom entendimento do tecido. (PANERAI, 2014: 86)

Para Panerai a cidade é vista como obra de arte, como artefato. Pode-se perceber isso ao serem analisados os mapas cadastrais, que demostram as plantas baixas das edificações, onde se representa uma cidade através de seus edifícios. 


\section{XI1}

\section{Bibliografia}

LAMAS, JOSÉ M. RESSANO GARCIA. (2004) Morfologia urbana e desenho da cidade. 3. ed. Lisboa: Fundação Calouste Gulbenkian.

MEGALE, NILZA BOTELHO. (2002) Memórias Históricas de Poços de Caldas. Poços de Caldas, MG: Sulminas.

MOURÃO, BENEDICTUS MÁRIO. (1998) Quarteto Construtor de Poços de Caldas e Epopéia de Pedro Sanches. Edição do Autor. Poços de Caldas, MG: Gráfica SULMINAS.

OTTONI, H. B. (1960) Poços de Caldas. São Paulo: Anhambi.

PANERAI, PHILIPPE. (2014) Análise urbana / Philippe Panerai; tradução de Francisco Leitão; revisão técnica de Sylvia Ficher. Brasília: Editora Universidade de Brasília.

SALLES, INSTITUTO MOREIRA. (1993) Memórias de Poços de Caldas- Poços de Caldas: Casa da Cultura de Poços de Caldas.

\subsubsection{Fontes eletrônicas}

DIAS, LUCIANA VALIN GONÇALVES. (2016) Um estudo de morfologia urbana da cidade de Poços de Caldas / Luciana Valin Gonçalves Dias. - Campinas: PUC Campinas. Disponível em: http://tede.bibliotecadigital.puc-

campinas.edu.br:8080/jspui/bitstream/tede/915/2/LUCIANA\%20VALIN\%20GON\%C3\%87ALVES\%20DIAS.pd p (consulta: 26/02/2020).

LOUREIRO. Planta aproximada do lugar onde nascem as Caldas. 1826. 1 mapa ms., desenho a tinta ferrogálica, $23,6 \times 38,3 \mathrm{~cm}$ em f. $24,6 \times 40,5 \mathrm{~cm}$. Escala [ca.1:2.666] Disponível em: http://objdigital.bn.br/objdigital2/acervo_digital/div_cartografia/cart525961/cart525961.jpg. 06/03/2020).

(consulta: 